\title{
Oxygen Use in Critical Illness
}

\author{
B Ronan O’Driscoll and Rachel Smith
}

\author{
Introduction \\ The Discovery of Oxygen \\ History of Medical Use of Oxygen \\ Reasons to Use Oxygen in Critical Care \\ History of Oxygen Use in Critical Care \\ Evidence of Harm From Excessive Use of Oxygen in Critical Care \\ Survivors of Cardiopulmonary Resuscitation \\ Ventilated General Critical Care Patients \\ Stroke Patients on Critical Care Units \\ Traumatic Brain Injury Patients on Critical Care Units \\ Myocardial Infarction \\ Pilot Studies of Conservative Oxygen Management for Ventilated Critical \\ Care Patients \\ Randomized Trials of Oxygen Therapy in Critical Care Settings \\ Why Have Clinicians Used Too Much Oxygen for Many Decades? \\ Current Best Practice for Oxygen Use in Critical Illness \\ Overview \\ Immediate Management of Critical Illness in Pre-Hospital Settings \\ Immediate Management of Critical Illness in Hospital Settings \\ Oxygen Use in Critical Care Units \\ Choice of Device \\ The Role of the Respiratory Therapist \\ Special Uses of Oxygen \\ Oxygen as a Driving Gas for Nebulizers \\ Carbon Monoxide Poisoning \\ Hyperbaric Oxygen \\ Medically Managed Pneumothorax \\ Oxygen and Avoidance of Perioperative Wound Infection \\ Future Directions
}

\begin{abstract}
Oxygen is the most commonly used drug in critical care. However, because it is a gas, most clinicians and most patients do not regard it as a drug. For this reason, the use of medical oxygen over the past century has been driven by custom, practice, and "precautionary principles" rather than by scientific principles. Oxygen is a life-saving drug for patients with severe hypoxemia, but, as with all other drugs, too much can be harmful. It has been known for many decades that the administration of supplemental oxygen is hazardous for some patients with COPD and other patients who are vulnerable to retention of carbon dioxide (ie, hypercapnia). It has been recognized more recently that excessive oxygen therapy is associated with significantly increased mortality in critically ill patients, even in the absence of risk factors for hypercapnia. This paper provides a critical overview of past and present oxygen use for critically ill patients and will provide guidance for safer oxygen use in the future. [Respir Care 2019;64(10):1293-1307. (C) 2019 Daedalus Enterprises]
\end{abstract}




\section{OXYGEN Use IN CRITICAL ILLNESS}

\section{Introduction}

Critical illnesses such as major trauma, pneumonia, sepsis, or heart failure can cause dangerously low blood oxygen levels (ie, hypoxemia), which can cause tissue damage and death. ${ }^{1}$ For this reason, avoidance of hypoxemia is a central tenet of the emergency medical response to critical illness. The first two elements of the "ABC" of emergency care refer to ensuring oxygenation by attention to the airway and breathing, and the third element (ie, circulation) is also critical to deliver oxygen to the tissues. For these reasons, oxygen therapy became a central component of resuscitation and critical illness management during the 20th century. The prevailing philosophy regarding oxygen use during that century was that "more is better."

There was no awareness in the 20th century that highconcentration oxygen therapy could be harmful apart from special circumstances such as in the care of hypercapnic patients with exacerbations of COPD, who were known since the 1960s to require controlled oxygen therapy, and in the care of premature babies, in whom excessive oxygen therapy was recognized since the 1950 s as a cause of blindness. ${ }^{1,2}$ There was no reliable way of knowing if a patient was adequately oxygenated until they arrived at the hospital and had invasive blood gas measurements. Outside of critical care units, blood gas tests could be undertaken only intermittently, and repeated arterial sampling is traumatic for patients. In these circumstances, it is understandable that 20th-century clinicians managing patients with critical illness administered oxygen lavishly to avoid hypoxemia, and they had no concerns regarding possible harm from hyperoxemia outside of the special groups of patients mentioned above.

However, with the advent of ubiquitous cheap and reliable pulse oximeters in the early 21 st century, alongside increasing knowledge regarding the dangers of hyperoxemia and the lack of evidence of any benefit from aggressive oxygen therapy, the use of oxygen in critical care in the 21st century should be very different from what happened in the previous century. In 2002, in his prestigious Donald F Egan Scientific lecture to the 48th International Respiratory Congress of the American Association for Respiratory Care, John Downs concluded that supplemental

Dr O'Driscoll and Ms Smith are affiliated with the Department of Respiratory Medicine, Salford Royal University Hospital, Salford, United Kingdom.

The authors have disclosed no conflicts of interest.

Correspondence: B Ronan O'Driscoll MD FRCP, Department of Respiratory Medicine, Salford Royal University Hospital, Stott Lane, Salford M6 8HD, United Kingdom. E-mail: ronan.o.driscoll@srft.nhs.uk.

DOI: $10.4187 /$ respcare. 07044 oxygen was much overused. ${ }^{3}$ He exposed 3 fallacies that will be discussed further in this review. First, there was a belief that exposure to supplemental oxygen at concentrations up to $60 \%$ was without adverse effects. Second, it was thought that patients at risk of developing arterial hypoxemia could be protected by administering supplemental oxygen. Third, it was thought that routine administration of supplemental oxygen was useful, harmless, and clinically indicated on a prophylactic basis.

Since 2002, there have been numerous publications that have supported Downs' view that supplemental oxygen has been overused, but clinical practice has been slow to evolve. This review will explain the principles underlying contemporary oxygen therapy together with an outline of oxygen use in the management of critically ill patients in the past and guidance for safe oxygen use in the management of critical illness in the future. The authors will try to explain why clinical practice in this area has been so slow to change and why it has been so difficult to translate research findings into routine care.

\section{The Discovery of Oxygen}

It was thought in the 18th century that the process of combustion gave off a chemical called phlogiston; it is now known that combustion (and animal respiration) actually involves the consumption of oxygen. An English scientist, theologian, and polymath named Joseph Priestley (the inventor of soda water and thus of all fizzy drinks) isolated a colorless gas by heating mercuric oxide. This gas allowed candles to burn brighter and for longer, and it prolonged the life of mice in sealed containers. Priestley thought he had discovered something he called dephlogisticated air. A similar discovery was made by a Swedish chemist named Carl Scheele at about the same time, but Priestley got most of the credit because he published first. It was the French chemist, Lavoisier, who recognized that Priestley and Scheele had actually discovered a new gas, which he called oxygen. It is fascinating to observe that Priestley recognized the potential medical uses of oxygen, as well as the potential risks of accelerating oxidative processes when he watched candles flare up in this new gas. He issued the following prophetic words in 1776:

From the greater strength and vivacity of the flame of a candle, in this pure air, it may be conjectured, that it might be particularly salutary to the lungs in certain morbid cases, when the common air would not be sufficient to carry off the phlogistic putrid effluvium fast enough. But, perhaps, we may also infer from these experiments, that though pure dephlogisticated air might be useful as a medicine, it might not be so proper for us in the usually healthy state of the body; for as a candle burns out much faster in dephlogisiticated than in common air, so we might, as may be 


\section{OXYGEN Use IN CRITICAL ILLNESS}

said, live out too fast, and the animal powers be too soon exhausted in this pure kind of air.

\section{History of Medical Use of Oxygen}

Attempts to use oxygen for medical benefit began in the late 18th century within a few years of the discovery of oxygen, and these attempts continued through the 19th century. As early as 1798, Thomas Beddoes founded the pneumatic institution for inhalation gas therapy in Bristol using oxygen and other gases, including nitrous oxide (ie, laughing gas) manufactured by the famous scientist, Humphrey Davy. For more than 100 years, the most common indication for oxygen use was in the treatment of pulmonary tuberculosis, which was a common cause of death in the 19th century. Unfortunately, supplies of oxygen were limited at that time, and the intermittent application of oxygen via primitive face masks was probably of little clinical benefit to cyanotic patients with end-stage pulmonary tuberculosis, for which there was no effective treatment until the mid-20th century.

Medical oxygen first came into widespread use in the management of soldiers who had inhaled toxic gases during the World War I. The pioneer of this work was a Scottish physiologist, John Scott Haldane, who also invented the gas mask. Like Priestley, Haldane had a premonition that oxygen treatment would be harmful if overused. He wrote the following in his historic publication regarding oxygen use in 1917: "The probable risks of prolonged administration of pure oxygen must be borne in mind, and if necessary balanced against the risks of allowing the oxygen want to continue."

The prophetic words of Priestley and Haldane went unheeded over the course of the 20th century, and oxygen came to be used not just for patients with potential hypoxemia but for virtually every type of medical emergency to the extent that the presence of an oxygen mask became an essential prop in every movie scene that involved acute illness. An audit of oxygen use in United Kingdom ambulances in 2008 found that $34 \%$ of ambulance patients were given supplemental oxygen therapy, even though only $17 \%$ had oxygen saturation $<94 \%$ and only $7 \%$ were significantly hypoxemic with saturation $<90 \%{ }^{4}$

\section{Reasons to Use Oxygen in Critical Care}

Many serious illnesses result in hypoxemia due to impaired gas exchange in the lungs, which in turn may be caused by a variety of factors, including direct pulmonary injury (eg, pneumonia or major trauma) and indirect factors such as disordered hemodynamics in sepsis, shock, cardiac arrest, or pulmonary embolism. Hypoxia may also be the result of reduced ventilation as a consequence of opioid analgesics or painful respiration. Because oxygen is the main fuel for the metabolism of the cells and organs of animals and humans, a major fall in the tissue oxygen level will produce rapid and severe injury to several organs, especially the brain, which is the most vulnerable organ in hypoxic conditions. Hypoxia is common in critical illness, and hypoxic brain damage is one of the most feared complications of hypoxia. Furthermore, a high proportion of patients in critical care units require mechanical ventilation, which usually involves the use of supplemental oxygen above the level of room air (ie, 21\% oxygen). It is for these reasons that supplemental oxygen is administered to the majority of patients in critical care units.

Patients with medical emergencies who are hypoxemic are more likely to die than those with normal blood oxygen levels. ${ }^{5}$ However; it is difficult to know in most cases whether the increased risk of death is a consequence of the low blood oxygen level itself or just a marker of disease severity. It is self-evident that an episode of pneumonia that is sufficiently severe to cause hypoxemia is more serious (and more likely to result in death) than a milder episode of pneumonia in a normoxemic patient. What is not known is the effect of oxygen therapy on the likelihood of survival in these circumstances. The level of hypoxemia that is dangerous to human life is unknown and probably varies depending on the cause of hypoxemia, the speed of onset of hypoxemia, and the underlying condition of the patient. Pending future studies, it is believed that patients with serious illness and oxygen saturation $<90 \%$ are likely to benefit from supplemental oxygen therapy. ${ }^{1,6,7}$ However, as discussed in detail below, there is little evidence of benefit from the administration of oxygen to patients with $\mathrm{S}_{\mathrm{PO}_{2}}$ above this level, and there is evidence of harm if the patient is rendered hyperoxemic by the use of supplemental oxygen.

Oxygen was used in the past as a routine supplemental measure with little thought regarding the purpose of this treatment. However, as discussed below, it is now recognized that giving too much oxygen may be as dangerous as giving too little oxygen, although the consequences of hyperoxemia are not as immediate nor as obvious to clinicians as the consequences of sudden hypoxemia.

\section{History of Oxygen Use in Critical Care}

Intensive care units and blood gas analysis were first developed in Copenhagen in the 1950s in response to a polio epidemic, which caused hundreds of cases of respiratory failure. The specialty of intensive care was further developed in the United States and in Europe in the 1960s and 1970s. ${ }^{8}$ The first ventilators were "iron lung" curaisse devices that did not necessarily involve oxygen therapy. These were soon succeeded by mechanical ventilators, which required entrained gases. Invasive ventilation almost always involved the use of oxygen above the envi- 
ronmental level of $21 \%$. Intensive care units also developed the capacity to artificially support other organ systems including renal replacement, cardiovascular support and enteral and parenteral nutrition.

The early decades of critical care medicine involved increasingly aggressive measures to "normalize" the patient's physiology and biochemistry. Sadly, most of these measures, such as aggressive blood transfusion, are now known to have been harmful. Recent research has shown that this is also true for aggressive or unnecessary oxygen therapy.

Most critical care patients and virtually all ventilated critical care patients are administered supplemental oxygen at a higher concentration than ambient air, which contains $21 \%$ oxygen. Supplemental oxygen therapy can range from $24 \%$ to $100 \%$ oxygen, but the safest oxygen level for critical care patients is not known, and the optimal oxygenation goal should probably be adjusted to the patient's specific circumstances. For example, it is generally agreed that patients with acute lung injury should have lower oxygenation targets than other critical care patients. ${ }^{9}$ Unfortunately, we do not yet know which levels of oxygenation are best for most medical conditions.

Oxygen levels in critical care units are monitored with the use of continuous pulse oximetry, which displays a percentage $\left(\mathrm{S}_{\mathrm{pO}_{2}}\right)$. Pulse oximeter values of $94-98 \%$ are generally taken to be normal, and values $<90 \%$ have been considered as cause for concern. ${ }^{1}$ Blood gas measurements, which include arterial oxygen and carbon dioxide tensions $\left(\mathrm{P}_{\mathrm{aO}_{2}}\right.$ and $\left.\mathrm{P}_{\mathrm{aCO}}\right)$, in addition to blood $\mathrm{pH}$, bicarbonate, and lactate levels, are also measured intermittently in samples of arterial blood drawn from intra-arterial catheters, direct radial artery sampling, or arterialized capillary samples. ${ }^{1}$

A consensus conference on mechanical ventilation in 1993 concluded as follows:

\begin{abstract}
A critical objective of mechanical ventilation is to achieve and maintain a level of arterial blood oxygenation that is acceptable for the clinical setting, using an $\mathrm{F}_{\mathrm{IO}_{2}}$ that is also acceptable. In most applications of ventilatory support, this means a $\mathrm{S}_{\mathrm{aO}_{2}}>90 \%$ (roughly equivalent to $\mathrm{a}_{\mathrm{aO}_{2}}>60 \mathrm{~mm} \mathrm{Hg}$ or $8 \mathrm{kPa}$, assuming a normal position of the oxyhemoglobin dissociation curve), although other end points are appropriate in certain settings. There is no clinical evidence that a $\mathrm{P}_{\mathrm{aO}_{2}}$ greater than normal is advantageous. ${ }^{6}$
\end{abstract}

Despite this guidance from 26 years ago, there was an ongoing climate until quite recently where blood oxygen levels at the top end of the normal range or in varying degrees of hyperoxemia were the norm on critical care units throughout the world. For example, the mean $\mathrm{P}_{\mathrm{aO}_{2}}$ of 36,307 ventilated critical care subjects in the Netherlands in $1999-2006$ was $12.4 \mathrm{kPa}(93 \mathrm{~mm} \mathrm{Hg}$ ), and the mean
$\mathrm{P}_{\mathrm{aO}_{2}}$ among 152,680 ventilated critical care subjects in Australia and New Zealand was $20.3 \mathrm{kPa}(152 \mathrm{~mm} \mathrm{Hg})$ over the period of 2000-2009, although the normal range is just $75-100 \mathrm{~mm} \mathrm{Hg}(10.5-13.5 \mathrm{kPa}) .^{10,11}$ An audit of 17,292 blood gas samples from the ICU at Salford Royal Hospital in the United Kingdom in 2015 showed a mean oxygen saturation of $95.7 \% .^{12}$ The percentage of samples with saturation $>98 \%$ fell from $57 \%$ in 2005 to $43 \%$ in 2010, and it fell further to $29 \%$ in the repeat audit in 2015. In 2005, the mean $\mathrm{P}_{\mathrm{aO}_{2}}$ of Salford critical care patients was $15.1 \mathrm{kPa}(113 \mathrm{~mm} \mathrm{Hg})$. This was reduced to $14.9 \mathrm{kPa}$ in 2010 and to $13.5 \mathrm{kPa}$ in 2015 . These findings suggest that oxygen use in critical care has become more conservative in recent years, which is in line with a growing literature suggesting possible harm from very high blood oxygen tension as discussed below. Recent guidance for ventilated patients on critical care units recommends aiming for normoxemia or consideration of permissive hypoxemia. Evidence for the latter strategy is limited and mainly based on observational data. ${ }^{13}$

\section{Evidence of Harm From Excessive Use of Oxygen in Critical Care}

The high prevalence of elevated blood oxygen tensions in critical care units in several countries (discussed above) is of concern because a number of retrospective observational studies and one prospective randomized study have identified increased mortality in association with hyperoxemia as well as the expected increase in mortality that is associated with hypoxemia.

There is evidence that high fractions of inspired oxygen are directly harmful to lung tissue. In the 19th century, exposure to $73 \%$ oxygen at atmospheric pressure for $4 \mathrm{~d}$ was reported to cause fatal pneumonitis in rats, and similar problems have been described in mice, likely mediated by enhanced reactive oxygen species activity. ${ }^{14-16}$ Griffith et al reported in 1986 that breathing 50\% oxygen for $45 \mathrm{~h}$ led to evidence of pulmonary leakage and inflammation in normal human volunteers. ${ }^{17}$

Oxygen is also known to lead to atelectasis and coronary and cerebral vasoconstriction. ${ }^{18,19}$ In addition to the direct and indirect effects of oxygen therapy itself, some patients are difficult to ventilate, and it is possible that aggressive strategies used to "normalize" the oxygen saturation (eg, high inflation pressures) may themselves be harmful to the lungs. A number of retrospective studies and 4 systematic reviews have concluded that hyperoxemia is consistently associated with increased in-hospital mortality in several subsets of critically ill subjects. ${ }^{20-23}$

\section{Survivors of Cardiopulmonary Resuscitation}

Kilgannon et $\mathrm{al}^{24}$ reported an increased risk of in-hospital mortality (adjusted odds ratio for death $=1.8$ ) for 
6,326 subjects after cardiopulmonary resuscitation who had $\mathrm{P}_{\mathrm{aO}_{2}}>300 \mathrm{~mm} \mathrm{Hg}(>40 \mathrm{kPa})$ on their first critical care unit blood gas measurement. A subsequent paper by Kilgannon et $\mathrm{al}^{25}$ showed that this was a linear dose-response relationship. Bellomo et $\mathrm{al}^{26}$ looked at the lowest oxygen level (worst A-a gradient) in the first $24 \mathrm{~h}$ in the critical care unit for 12,108 post resuscitation subjects and they reported a mortality rate of $59 \%$ in the hyperoxia group $\left(\mathrm{P}_{\mathrm{aO}_{2}}>300 \mathrm{~mm} \mathrm{Hg}\right)$ compared with a $47 \%$ mortality rate among subjects with $\mathrm{P}_{\mathrm{aO}_{2}}$ in the $60-300 \mathrm{~mm} \mathrm{Hg}$ range. The adjusted odds ratio for death was 1.2, although the investigators concluded that "hyperoxia did not have a robust or consistently reproducible association with mortality." Curiously, for a study of the impact of hyperoxemia, they did not look at the average or highest oxygen level of these subjects, which might have been more appropriate. Elmer and colleagues ${ }^{27}$ reported a small single-center study in 2015 in which severe hyperoxemia $\left(\mathrm{P}_{\mathrm{aO}_{2}}>300 \mathrm{~mm} \mathrm{Hg}\right.$ or $40 \mathrm{kPa}$ ) was associated with increased hospital mortality, whereas moderate hyperoxemia (101-299 $\mathrm{mm} \mathrm{Hg}$ ) was not associated with decreased survival. A number of smaller studies have also been published, and a systematic review and meta-analysis by Wang and colleagues ${ }^{20}$ concluded that hyperoxemia appears to be correlated with increased in-hospital mortality in survivors of adult cardiac arrest, although the results should be interpreted cautiously because of the significant heterogeneity and the limited number of studies that were analyzed.

\section{Ventilated General Critical Care Patients}

de Jonge et $\mathrm{al}^{10}$ reviewed the management of 36,307 ventilated critical care subjects and reported increased mortality (odds ratio $=1.23$ ) if the mean $\mathrm{P}_{\mathrm{aO}_{2}}$ in the first $24 \mathrm{~h}$ in hospital was $>16.4 \mathrm{kPa}(123 \mathrm{~mm} \mathrm{Hg})$. Optimal survival was in the quintile of subjects with $\mathrm{P}_{\mathrm{aO}_{2}}=8.9-10.6 \mathrm{kPa}$ (67-79 $\mathrm{mm} \mathrm{Hg}$ ), equivalent to saturation of approximately 93-96\% at normal $\mathrm{pH}$. Eastwood et $\mathrm{al}^{11}$ looked at the lowest oxygen level in the first $24 \mathrm{~h}$ (worst A-a gradient) for 152,680 ventilated critical care subjects with mean $\mathrm{P}_{\mathrm{aO}_{2}}=20 \mathrm{kPa}(150 \mathrm{~mm} \mathrm{Hg})$. They reported an association of hypoxemia (but not hyperoxemia) with mortality.

A 2017 observational study by Helmerhorst et al ${ }^{28}$ reported that mortality in ICU subjects was increased with marked hyperoxia ( $>200 \mathrm{~mm} \mathrm{Hg}$ or $27 \mathrm{kPa}$ ), and time spent in hyperoxemia showed a linear relationship with hospital mortality. Two recent systematic reviews with meta-analysis have addressed this subject. ${ }^{21,22}$ Both studies concluded that hyperoxemia was associated with increased hospital mortality, but caution is required in interpreting the results because of heterogeneity in the included studies, including different definitions of hyperoxemia.

\section{Stroke Patients on Critical Care Units}

Rincon et al ${ }^{29}$ analyzed 2,894 stroke subjects treated on critical care units and reported a crude odds ratio of 1.7 for hospital mortality among subjects with $\mathrm{P}_{\mathrm{aO}_{2}}>300 \mathrm{~mm} \mathrm{Hg}$ compared with normoxia. After multivariate analysis, the adjusted odds ratio was 1.2 (95\% CI 1.04-1.5). In a quasirandomized trial, increased mortality was also reported in stroke subjects on general wards with mild to moderate stroke severity who were given oxygen. ${ }^{30}$ However, this was not confirmed in a much larger study of stroke subjects managed outside of critical care units $(N=8,003$ subjects). ${ }^{31}$ This study found that routine low-dose oxygen treatment at $2-3 \mathrm{~L} / \mathrm{min}$ from nasal cannula did not reduce (or increase) mortality or improve recovery even for subjects with oxygen saturation in the range of $90-94 \%$.

\section{Traumatic Brain Injury Patients on Critical Care Units}

Rincon et $\mathrm{al}^{32}$ reported an increased risk of hospital death among 1,212 ventilated subjects with traumatic brain injury on critical care units if they were exposed to hyperoxia (crude odds ratio (and adjusted odds ratio) for death was 1.5 if exposed to $\mathrm{P}_{\mathrm{aO}_{2}}>300 \mathrm{~mm} \mathrm{Hg}$ ). Mortality was also increased with exposure to hypoxemia (crude odds ratio for hospital death was 2.3 for subjects with $\mathrm{P}_{\mathrm{aO}_{2}}$ $<60 \mathrm{~mm} \mathrm{Hg}$ (7.99 kPa, equivalent to saturation of approximately $90-91 \%$ ) or a $\mathrm{P}_{\mathrm{aO}_{2}} / \mathrm{F}_{\mathrm{IO}_{2}}$ ratio $\leq 300$.

\section{Myocardial Infarction}

Patients with suspected myocardial infarction have been given supplemental oxygen on a routine basis for several decades in the hope that this might increase oxygen delivery to the ischemic area of myocardium. As recently as 2010, an editorial in the British Medical Journal stated that "it is reasonable to continue giving oxygen to people with acute myocardial infarction." 33 This advice was given on the basis that the increased mortality that was associated with hyperoxia in a linked systematic review failed to reach statistical significance. This suggestion (that a drug should be given to all patients with a common condition where there is no evidence of benefit but weak evidence of harm) must be unique to oxygen. Since that time, there have been 3 randomized trials of oxygen use in myocardial infarction. ${ }^{34-36}$ None of these studies suggested any benefit for normoxic subjects, but the study by Stub and colleagues, ${ }^{35}$ which was undertaken in the pre-hospital environment with subjects with confirmed myocardial infarction, reported higher levels of cardiac enzymes and larger infarct size on follow-up magnetic resonance scans in subjects randomized to receive supplemental oxygen. A 2018 meta-analysis of these trials and all preceding trials found no evidence of benefit from supplemental oxygen in nor- 
moxic subjects with myocardial infarction but could not rule out a harmful effect. ${ }^{37}$ It is also important to note that a proportion of subjects in some of these trials who were randomized to air had already received oxygen in prehospital care prior to randomization, so the true risks of routine oxygen use in patients with suspected myocardial infarction may be underestimated in some of the included studies.

\section{Pilot Studies of Conservative Oxygen Management for Ventilated Critical Care Patients}

There are 4 published pilot studies of conservative oxygen management in critical care subjects. ${ }^{38-41}$ All of these studies have demonstrated that such an approach is safe

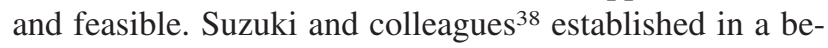
fore-and-after pilot study of 105 subjects in 2014 that conservative oxygen therapy for mechanically ventilated subjects (target $\mathrm{S}_{\mathrm{pO}_{2}}=90-92 \%$ ) was feasible and free of adverse biochemical, physiological, or clinical outcomes while allowing a marked decrease in excess oxygen exposure. Within this study, the authors reported a lower incidence of atelectasis on chest radiograph in subjects allocated to conservative oxygen therapy (odds ratio $=0.28$, $95 \%$ CI $0.12-0.66, P=.003$ ) and earlier successful weaning from mechanical ventilator (adjusted hazard ratio $=2.96,95 \%$ CI 1.73-5.05, $P<.001) .{ }^{38,39}$ Eastwood and colleagues reported in a linked study of 100 subjects that a target oxygen saturation range of $88-92 \%$ was feasible for mechanically ventilated cardiac arrest survivors and resulted in more use of spontaneous ventilation mode (ie, less mandatory ventilation), more ventilation on air $\left(\mathrm{F}_{\mathrm{IO}_{2}}=0.21\right)$, and shorter stay on the critical care unit. ${ }^{40}$

Panwar et $\mathrm{al}^{41}$ completed a multi-center, randomized, controlled pilot trial of conservative (target range 88-92\%) versus liberal (target range $\geq 96 \%$ ) oxygen therapy for 103 mechanically ventilated subjects. They reported clear separation of oxygen levels, and although 90-d mortality was reduced in the conservative oxygen group (adjusted hazard ratio $=0.77,95 \%$ CI $0.40-1.5, P=.44$ ), this was not significant in this small study. They did not identify any difference in the duration of mechanical ventilation or ventilator-free days between the subject groups.

Helmerhorst ${ }^{42}$ reported a before-and-after study in which a target range was set at $\mathrm{S}_{\mathrm{pO}_{2}}=92-95 \%$ or $\mathrm{P}_{\mathrm{aO}_{2}}=55-$ $86 \mathrm{~mm} \mathrm{Hg}(7.3-11.5 \mathrm{kPa})$. They reported shorter periods of mechanical ventilation (an increase of 0.55 ventilatorfree days) in phase 1 of implementation (95\% CI 0.25 0.84 ) and $0.44 \mathrm{~d}$ in phase 2 (95\% CI $0.11-0.86$ ). They also reported no difference in adjusted critical care unit mortality or ventilator-free days, but hospital mortality decreased in reference to baseline. The adjusted odds ratio in phases 1 and 2 were $0.84(0.74-0.96)$ and $0.82(0.69-$ $0.96)$, respectively.
These pilot studies support the view that conservative oxygen management may reduce mortality and duration of ventilation. Importantly, none of the 4 pilot studies raised any safety concerns related to the conservative use of oxygen on critical care units.

\section{Randomized Trials of Oxygen Therapy in Critical Care Settings}

A randomized trial of conservative oxygen therapy in critical care subjects with expected critical care unit stay of $>72 \mathrm{~h}$ was published in October 2016.43 This Italian study reported a critical care unit mortality rate of $11.6 \%$ in subjects randomized to a target saturation range of 94 $98 \%$ (median $\mathrm{P}_{\mathrm{aO}_{2}}=11.6 \mathrm{kPa}$ ) compared with $20.2 \%$ critical care unit mortality with conventional therapy (median $\mathrm{P}_{\mathrm{aO}_{2}}=13.6 \mathrm{kPa}$ ). The absolute risk reduction was $8.6 \%(P=.01)$ and the hospital mortality rate was $24.2 \%$ versus $33.9 \%$ (absolute risk reduction $9.9 \%(P=.03)$. The authors urged caution in the interpretation of these results because the trial was terminated early due to slow recruitment, although statistical significance was achieved for the primary and secondary end points. A larger trial of targeted oxygen use in critical care (ICU-ROX study) is due to report in the very near future; the pilot study suggested that critical care stay may be shortened by the use of conservative oxygen therapy. ${ }^{44}$

A randomized trial of hyperoxia in subjects with septic shock showed a nonsignificant increase in 28-d mortality associated with hyperoxia ( $43 \%$ vs $35 \%, P=.12$ ). ${ }^{45} \mathrm{Un}-$ fortunately, the trial was terminated prematurely because of an increase in 2 secondary end points in the hyperoxia group (ie, atelectasis and ICU weakness).

\section{Why Have Clinicians Used Too Much Oxygen for Many Decades?}

First, old habits die hard. Aggressive oxygen use for seriously ill patients with unknown blood oxygen levels was justified 100 years ago, but this is no longer true. Tuberculosis and pneumonia were common in the early 20th century, and there were no effective treatments for either of these conditions. In these circumstances, correction of hypoxemia could, in some cases, prevent death until such time as the body's natural defenses had overcome the pulmonary injuries. This also applied to victims of gas attacks in World War I. At that time, there was no way to monitor blood oxygen levels, so clinicians administered oxygen blindly. Precautionary oxygen use became standard practice, and this habit persisted long after the introduction of routine blood gas sampling in the 1970s and the availability of cheap and reliable oximeter probes in the early 21 st century. 
Another reason for this longstanding habit is that clinicians are quick to take up new treatments, even if the costs are high and the benefits are modest. This is especially true of products that are heavily promoted by pharmaceutical companies, device manufacturers, and enthusiastic "pioneering" clinicians. However, the same clinicians tend to be slow to dispense with traditional practices, even if they have been proven to be ineffective or harmful. Unfortunately, there are many levers and incentives to promote the uptakes of new drugs and treatments, but there are few levers to curtail outmoded practices.

Furthermore, simple physiology tends to be forgotten or ignored. Oxygen is a treatment for hypoxemia, not for breathlessness. However, most lay people and many clinicians think that the symptom of breathlessness is caused mainly by low blood oxygen levels and that oxygen will relieve this, even if the blood oxygen saturation is normal. ${ }^{46,47}$ Disproving this fallacy requires only a volunteer and a pulse oximeter. Very few humans can hold their breath long enough to produce a significant fall in their blood oxygen saturation because our sense of breathlessness during breath-holding is caused mainly by failure to expel our exhaust gas (carbon dioxide). A rising level of carbon dioxide during breath-holding causes breathlessness long before the blood oxygen level falls. Ignorance of this fact has caused many deaths among free divers who may hyperventilate before a dive to prolong their dive time by taking in more oxygen. However, hyperventilation leads to only about $2 \%$ rise in blood oxygen content due to a rise in hemoglobin oxygen saturation from $98 \%$ to $100 \%$ in a typical healthy subject. This is in striking contrast to the $47 \%$ reduction in blood carbon dioxide levels that can be achieved after just two minutes of voluntary hyperventilation. ${ }^{48}$ This delays the onset of hypercapnia during the dive and allows a diver to stay underwater for longer before the onset of breathlessness. Unfortunately, a diver who has hyperventilated may remain submerged long enough for hypoxia to develop. The first symptom of hypoxia is disordered mental functioning (starting from saturation $<\sim 80 \%$ ), followed by the onset of unconsciousness as the oxygen saturation falls to $<\sim 56 \%$ in healthy individuals. ${ }^{49-52}$ If this happens before the diver surfaces, the consequences are likely to be fatal.

Raising the arterial oxygen saturation above the physiological range (about $96-98 \%$ for young adults and 94$98 \%$ for older adults) has very little effect on blood oxygen content because, by definition, the hemoglobin molecules in the blood are almost fully saturated with oxygen at these saturation levels, and very little oxygen is transported to the tissues by any other means. ${ }^{1}$ Giving supplemental oxygen therapy to raise the $\mathrm{P}_{\mathrm{aO}_{2}}$ to $>100 \mathrm{~mm} \mathrm{Hg}$ in a patient with $\mathrm{S}_{\mathrm{pO}_{2}}=98 \%$ can increase the oxygen saturation by only $2 \%$, even if the $\mathrm{P}_{\mathrm{aO}}$ is increased as high as $400 \mathrm{~mm} \mathrm{Hg}$ by the administration of high-concentration oxygen. This could be compared to keeping a gasoline pump running after the automatic cutoff point when filling your vehicle with gas. You might increase the amount of available gasoline marginally by filling the inlet pipe as well as the tank, but you might also spill a lot of gasoline on your shoes and possibly even cause an explosion.

In addition to these reasons, oxygen was used for many decades for precautionary reasons in situations such as postoperative care, where some patients might suffer from unexpected hypoxemia, sometimes with sudden onset. This practice may have been justified in the early 20th century when the blood oxygen level was unknown. Now that oximeters are almost universally available, the precautionary use of oxygen may actually delay the recognition of clinical deterioration and may limit the treatment options. As discussed by Downs ${ }^{3}$ in 2002, a patient who develops respiratory deterioration while breathing air is likely to have a gradual fall in routine $\mathrm{S}_{\mathrm{pO}_{2}}$ measurements, which will alert the clinical team to the deterioration, and they may commence supplemental oxygen therapy to stabilize the patient while definitive treatment for underlying problems, such as pneumonia or heart failure, is commenced. By contrast, if the same patient is using supplemental oxygen on a precautionary basis, the $\mathrm{S}_{\mathrm{pO}_{2}}$ levels are likely to remain reassuringly high even as the patient's physiology deteriorates. When the $\mathrm{S}_{\mathrm{pO}_{2}}$ does eventually fall, the patient will be at a more advanced stage of deterioration, and the therapeutic options are more limited because the patient is now hypoxemic despite oxygen therapy and may require rapid transfer to the critical care unit. The 20th century precaution has thus become a hazard to the 21 st century patient.

Yet another reason that oxygen is overused is that oxygen therapy became normalized and institutionalized. Patients and many clinicians came to regard oxygen as part of standard medical care for every seriously ill patient, a fashion that was likely influenced by the prominence of oxygen masks and tubes in medical television dramas and in 20th-century movies. Even in the 21st century, there remains a general impression among patients and health care professionals that oxygen is beneficial in most illnesses. ${ }^{46,47}$ Breathless patients and almost all seriously ill patients have been conditioned to expect oxygen treatment and clinicians have tended to meet this expectation even when the patient's oxygen saturation is already normal breathing air.

The widespread belief that oxygen is always beneficial is paralleled by widespread ignorance about the potential side effects of oxygen therapy, until very recently. ${ }^{46,47}$ In addition, clinicians like to be seen to do something, and it has been said that clinicians are sometimes treating themselves when they deliver a highly visible treatment such as 
Table 1. Key Principles of Oxygen Therapy

Oxygen is a treatment for hypoxemia. Giving oxygen does not relieve breathlessness, nor does it increase the oxygen supply to vital organs if the patient's oxygen level is normal to start with.

Aim for a normal or near-normal oxygen saturation level for most patients (94-98\% or 92-96\%).

Aim for a lower level for those at risk from hypercapnia (88-92\% or patient-specific range).

Prescribers prescribe a 'target range,' and clinicians adjust equipment and flows to keep $\mathrm{S}_{\mathrm{pO}_{2}}$ within the target range.

oxygen to a critically ill patient irrespective of the oximetry reading, especially if breathlessness is present. ${ }^{47}$

Finally, from a medico-legal perspective, deaths due to hypoxia in situations such as disconnection of anesthetic gas tubing or empty oxygen cylinders tend to be easy to identify and often lead to medico-legal claims. However, deaths due to hyperoxemia are like deaths due to air pollution. There is extensive evidence that both of these factors can increase death rates in vulnerable populations. Very few individual deaths are attributed to either hyperoxia or air pollution, although it is likely that both of these factors cause the deaths of many thousands of Americans every year. If Chu and colleagues ${ }^{23}$ are correct, patients with critical illness who have their blood oxygen saturation raised above $96 \%$ with supplemental oxygen may be $21 \%$ more likely to die than those treated with conservative oxygen therapy. Many clinicians continue to make their patients hyperoxemic by administering oxygen on a precautionary basis, possibly influenced in part by fear of censure or medico-legal claims. It is rare for such clinicians to suffer any censure. By contrast, most clinicians would be disciplined or worse if a patient's death was potentially the result of untreated hypoxemia. Clinicians would also be criticized if they withheld from critically ill patients a new treatment that reduced mortality by $21 \%$ but they are not presently criticized for administering an unnecessary treatment that may increase mortality by this amount.

\section{Current Best Practice for Oxygen Use in Critical Illness}

\section{Overview}

The consensus from most recent randomized trials, systematic reviews, and meta-analyses is that supplemental oxygen is indicated for patients with hypoxemia, but there is no evidence to support the use of oxygen for normoxemic patients (Table 1). The 2017 British Thoracic Society emergency oxygen guideline advises aiming for a target saturation of $94-98 \%$ for most patients with medical and surgical emergencies. ${ }^{1}$ The Thoracic Society of Australia and New Zealand recommends a target range of $92-96 \%$ (Table 2). ${ }^{53}$ The more recent advice from Siemieniuk et $\mathrm{al}^{7}$ is to aim even
Table 2. Suggested Oxygen Target Ranges for Patients With Serious Illness Who Are Not at Risk of Hypercapnia

\begin{tabular}{lc}
\hline \hline \multicolumn{1}{c}{ Guideline } & $\begin{array}{c}\text { Suggested Target Range } \\
\text { for Patients Who Are } \\
\text { Not at Risk of } \\
\text { Hypercapnia }\end{array}$ \\
\hline $\begin{array}{l}\text { British Thoracic Society } \\
\text { Thoracic Society of Australia } \\
\text { and New Zealand }\end{array}$ & $94-98 \%$ \\
Siemieniuk et al & \\
& $92-96 \%$ \\
& $90-94 \%$ for most patients \\
& $90-92 \%$ for those with \\
& stroke or myocardial \\
& infarction \\
\hline
\end{tabular}

lower with an upper limit of $96 \%$ for all patients on supplemental oxygen therapy, a target range of $90-94 \%$ for most

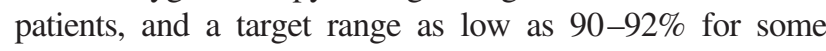
conditions such as stroke or myocardial infarction. Some critical care specialists suggest aiming even lower for certain patients requiring mechanical ventilation, especially those with acute lung injury, but randomized clinical trials of this strategy are urgently required. ${ }^{12}$

\section{Immediate Management of Critical Illness in Pre- Hospital Settings}

The immediate management of acute illness requires rapid assessment of the patient and immediate life-saving measures such as airway management if appropriate. The British Thoracic Society emergency oxygen guideline recommends the use of high-concentration oxygen from a reservoir mask (or bag-valve-mask) during the process of assessment and resuscitation for critically ill patients. However, once the patient is found to have stable cardiac output and a reliable oximetry trace can be obtained, clinicians should aim at a normal or near-normal oxygen saturation range such as $94-98 \%$ or $92-96 \%$, pending the availability of blood gas results. ${ }^{1,53}$ This advice also applies to survivors of cardiac arrest. The British Resuscitation Guideline recommends aiming for a saturation range of 94-98\% once spontaneous cardiac output has returned because post-arrest hyperoxia has been associated with increased mortality. ${ }^{54}$

There are some situations in which pulse oximetry is unreliable, such as the patient being in a state of shock or if the patient is thought to have carbon monoxide poisoning. In these situations, high-concentration oxygen should be administered until blood gas results (or carbon monoxide measurements) are available in the hospital setting. In some pre-hospital situations, such as mountain rescue or cave rescue, oximeters may be unavailable or impractical, and high-concentration oxygen should be used for critically ill patients in these situations until a reliable assessment of oxygenation can be made. 
Table 3. Oxygen Therapy Is Only One Element of Resuscitating a Critically Ill Patient

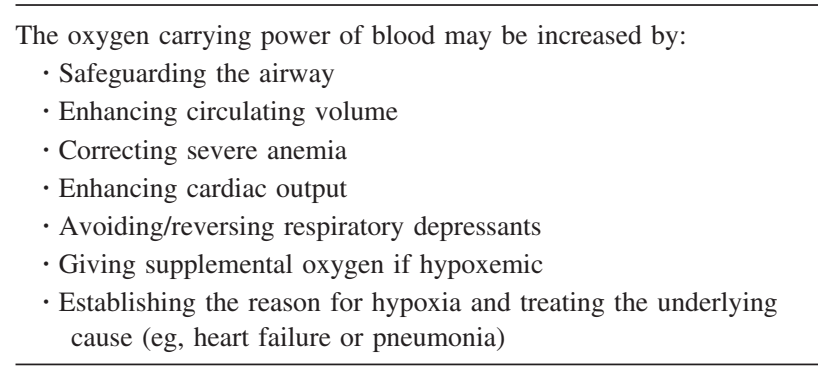

\section{Immediate Management of Critical Illness in Hospital Settings}

The immediate management of a patient who deteriorates suddenly in a hospital environment is similar to the immediate management of the pre-hospital patient discussed in the previous section, but the key difference is that expert personnel and blood gas measurements will be available much more quickly to guide optimal oxygen therapy (Table 3 ). In many hospitals, the critical care outreach team will be called to assess patients with sudden hypoxemia or other critical illness in the hospital. Supplementary oxygen is only required if the $\mathrm{S}_{\mathrm{aO}_{2}}$ is $<94 \%$ in most patients, or if the $\mathrm{S}_{\mathrm{aO}_{2}}$ falls to $<88 \%$ in patients who are at risk of hypercapnic respiratory failure. ${ }^{1}$ There is emerging evidence that an upper saturation limit of $96 \%$ should be applied to all acutely ill medical patients and that supplementary oxygen is not required in patients with acute stroke or acute myocardial infarction unless the saturation falls to $<92 \%$, with some evidence that the best threshold at which to start oxygen therapy in these groups may be $90 \%$ or lower. ${ }^{7,23,53}$ The patient should be continuously assessed using the $\mathrm{ABCDE}$ approach until stabilized, and a decision should be made as to whether the patient can be appropriately managed in the current location or if a higher level of care is required.

\section{Oxygen Use in Critical Care Units}

The vast majority of patients within the critical care unit will require supplementary oxygen to avoid hypoxemia, but there is increasing evidence that clinical outcomes may be worsened with hyperoxemia. Again, in the critical care unit it is recommended that, for patients receiving supplementary oxygen, an upper $\mathrm{S}_{\mathrm{pO}_{2}}$ limit of $96 \%$ should be set in acutely ill medical patients. In patients with stroke or myocardial infarction, supplementary oxygen should not be given if the $\mathrm{S}_{\mathrm{pO}_{2}}$ is $>92 \% .^{7}$ For patients at risk of hypercapnic respiratory failure, target $\mathrm{S}_{\mathrm{pO}_{2}}$ should be set at $88-92 \%$. These targets are likely to be adjusted in the future based on the results of further studies.

Oxygen-delivery systems in the critical care unit range from the traditional "standard-flow" systems, such as nasal cannula, simple face mask, and reservoir mask, to highflow humidified systems and oxygen delivered via noninvasive and invasive ventilators. Standard-flow systems (examples are shown in Fig. 1) deliver a flow 1-15 L/min,

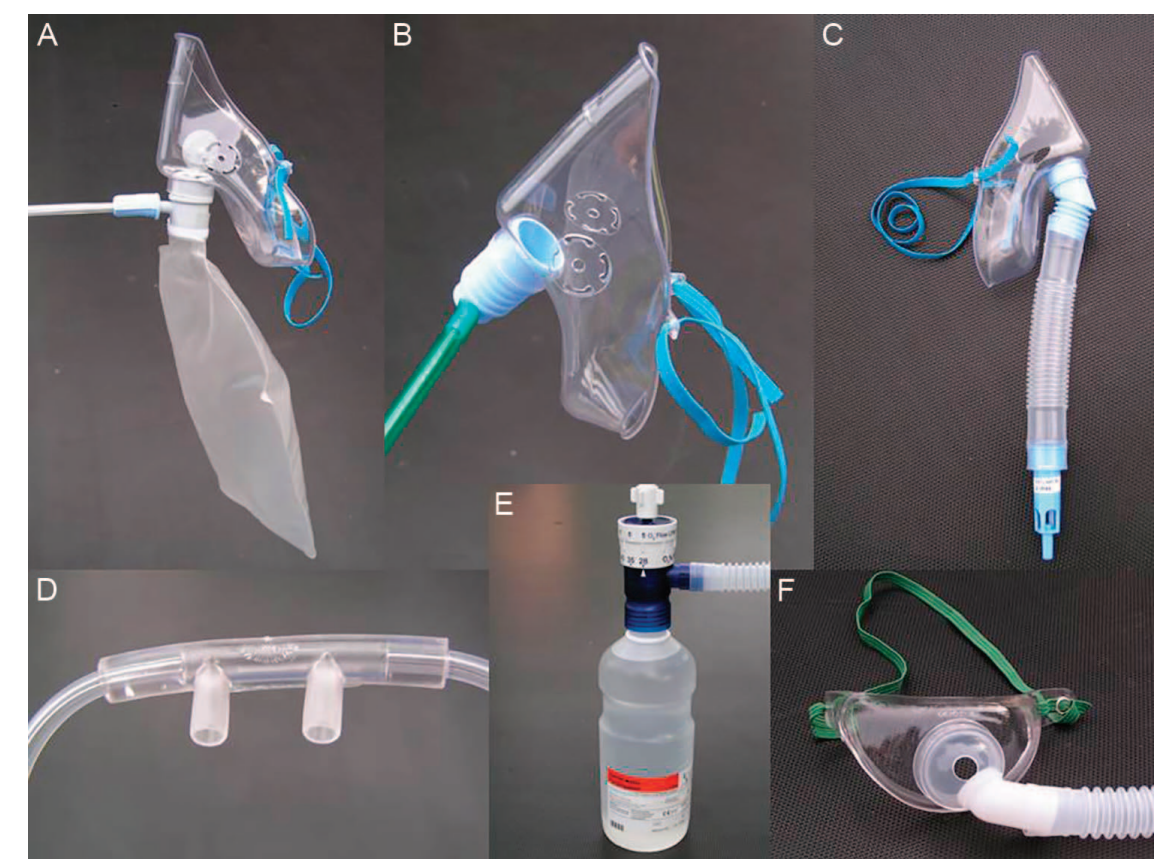

Fig. 1. Devices that are commonly used to deliver oxygen. A: Non-rebreathing reservoir mask; B: simple face mask; C: Venturi mask; D: low-flow nasal cannula; E: low-flow humidified system (unheated); F: tracheostomy mask. 


\section{OXYGEN Use IN CRITICAL ILLNESS}
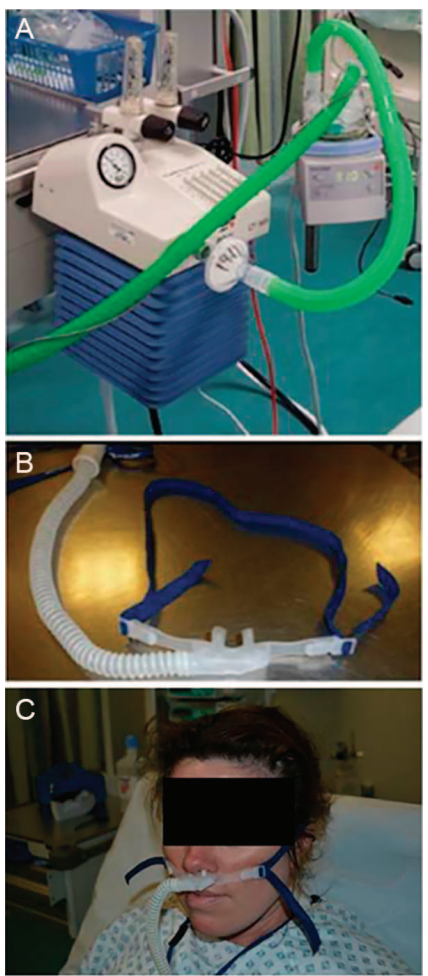

Fig. 2. High-flow humidified system. A: Flow generator and humidification system; B: high-flow nasal cannula; C: high-flow nasal cannula on a patient.

which is insufficient to meet the patient's flow requirement, therefore causing room air to be entrained, thus diluting the oxygen and reducing the amount of oxygen delivered to the patient at alveolar level. The amount of entrained air is variable, dependent of the mask fit, patient's breathing frequency, work of breathing, and tidal volume; therefore the amount of oxygen delivered can only be estimated.

Oxygen therapy via high-flow nasal cannula (HFNC) has increased in popularity, and its use is becoming widespread in the critical care unit (Fig. 2). Oxygen and air is mixed in a blender, warmed to $37^{\circ} \mathrm{C}$, and humidified, and then it is delivered to the patient at flows of 30-60 L/min. This is usually higher than the inspiratory flow of the patient which reduces the likelihood of air entrainment and allows the $\mathrm{F}_{\mathrm{IO}_{2}}$ to match that set at the blender. Several other effects have been documented, including pharyngeal dead space washout, reduction of nasopharyngeal resistance, generation of positive expiratory pressure (3.2$7.4 \mathrm{~cm} \mathrm{H}_{2} \mathrm{O}$ ), and alveolar recruitment; furthermore, humidification may play a role in improved tolerance and improved mucociliary clearance by helping patients maintain their secondary airway defense system..$^{55-57}$ Because flow and $\mathrm{F}_{\mathrm{IO}_{2}}$ are independent, the $\mathrm{F}_{\mathrm{IO}_{2}}$ can be reduced separately from the flow. Typically the flow is set at 50 $\mathrm{L} /$ min and the $\mathrm{F}_{\mathrm{IO}_{2}}$ is titrated to maintain target $\mathrm{S}_{\mathrm{pO}_{2}} \cdot \mathrm{F}_{\mathrm{IO}_{2}}$ is reduced initially until it reaches 0.4 , at which point flow can then be reduced and a switch to conventional oxygen therapy considered. ${ }^{56}$ There are, however, contradictory findings around the use and efficacy of nasal high-flow oxygen, with inconclusive evidence of its superiority to conventional oxygen therapy and noninvasive ventilation in the reduction of intubation rates, mortality rates, and re-intubation rates. ${ }^{58-62}$ These conflicting findings may be attributed to the different HFNC application strategies and patient conditions investigated in the studies. Although it may offer benefit in terms of patient comfort, care must be taken to avoid any inappropriate delay in initiation of invasive ventilation caused by inappropriate perseverance with HFNC.

Noninvasive and invasive mechanical ventilation will not be discussed in detail in this review; however, they allow the precise control of $\mathrm{F}_{\mathrm{IO}_{2}}$, manipulation of ventilator settings allowing optimization of ventilation to achieve adequate arterial oxygenation.

Regardless of the oxygen delivery system, the patient's oxygen saturations are usually monitored continuously in critical care units and recorded hourly as part of routine observation, in addition to the ready availability of arterial blood samples from arterial lines and arterialized capillary blood sampling. Ebmeier et al ${ }^{63}$ compared $\mathrm{S}_{\mathrm{pO}_{2}}$ and $\mathrm{S}_{\mathrm{aO}_{2}}$ in adult ICU patients, with the absence of a statistically significant bias in paired $\mathrm{S}_{\mathrm{pO}_{2}} / \mathrm{S}_{\mathrm{aO}_{2}}$ supporting the use of oximetry to regulate oxygen therapy, although care was advised when $\mathrm{S}_{\mathrm{aO}}$ recordings were $4.4 \%$ higher or lower than the $\mathrm{S}_{\mathrm{pO}_{2}}$. Regular monitoring and frequent review by the multidisciplinary team should lead to precise titration of oxygen to maintain prescribed targets. Although targets are regularly prescribed in the critical care unit, regular titration of oxygen does not always occur. This was clearly demonstrated in a study looking at goal-directed oxygen delivery based on $\mathrm{S}_{\mathrm{pO}_{2}}$; the investigators reported that the $\mathrm{S}_{\mathrm{pO}_{2}}$ was in the prescribed range $\sim 64 \%$ of the time. ${ }^{64}$ This was consistent with findings from the 2015 British Thoracic Society national audit of oxygen therapy in hospitals in the United Kingdom (Table 4). ${ }^{65}$

New systems for closed-loop control of oxygen therapy have been developed; initial findings indicate an improvement in controlling target saturation compared with manual titration; the use of these systems in clinical practice is rare, however, and there is a need to investigate the safety and efficacy of these devices in future trials. ${ }^{66,67}$

\section{Choice of Device}

The choice of device will depend on the patient's medical condition. Some common devices are shown in Figure 1 and Figure 2. Readers are referred to the British Thoracic 
Table 4. UK Hospital Patients With an Oxygen Prescription*

\begin{tabular}{lccccc}
\hline \hline & 2008 & 2011 & 2012 & 2013 & 2015 \\
\hline $\begin{array}{l}\text { Percent of UK hospital } \\
\text { patients using } \\
\text { oxygen at time of } \\
\text { national audit }\end{array}$ & 17 & 14 & 14 & 14 & 14 \\
$\begin{array}{l}\text { Percent of patients } \\
\text { using oxygen who } \\
\text { had a prescription }\end{array}$ & 32 & 48 & 52 & 55 & 57 \\
$\begin{array}{l}\text { Was oxygen signed for } \\
\text { on medicine rounds? }\end{array}$ & 5 & 20 & 20 & 21 & 28 \\
& & & & & \\
$*$
\end{tabular}

Society oxygen guideline for advice regarding when to use each type of mask or device and for advice regarding when to use humidified oxygen. ${ }^{1}$

\section{Role of the Respiratory Therapist}

As evidence-based health care becomes more available, one would assume that this would translate into enhanced patient care and improved outcomes; nevertheless, patients fail to receive care based on the best available evidence or current guidelines. ${ }^{68}$ Within health care, and also within critical care, it is well recognized that the process of translating evidence into practice is slow, and it is difficult to create a culture maintaining a change once it has been implemented. This has been well demonstrated within the field of critical care in the implementation of strategies such as low tidal-volume ventilation in the management of ARDS, which, similarly to oxygen titration, requires a change in mindset rather than additional resources or equipment. ${ }^{69}$

A significant barrier to change in culture is a lack of knowledge of the current literature and a lack of awareness of guidelines, often with staff believing they are meeting guidelines despite clinical practice differing from recommendations. ${ }^{70}$ Kelly and Maddon, ${ }^{70}$ in their study looking at how health care professionals perceive oxygen therapy, reported inconsistency in reported beliefs, understanding, and clinical practice.

Respiratory therapists, as specialists in respiratory care, possess increased knowledge and understanding around the prescription, delivery, and titration of oxygen therapy. Respiratory therapists have been shown to improve compliance in the delivery of protocol-driven care and in the implementation of standard guidelines. In the field of mechanical ventilation, RTs are instrumental in the delivery of ventilation and weaning. ${ }^{71}$ As such, RTs are in an ideal position to implement reform in targeted oxygen delivery. Strategies such as audit and feedback, provider education, protocol development, interventions to improve ICU teamwork, computer decision support, and behavioral economic interventions have been shown to assist in the implementation of low tidal-volume ventilation. ${ }^{69}$ In addition, the use of daily multidisciplinary team ward rounds with checklists, goal setting, and prompting have been shown to improve compliance with set targets. ${ }^{72}$ It is likely that these change principles can be utilized by respiratory therapists to effect a change in the practice and culture around the delivery of oxygen therapy.

\section{Special Uses of Oxygen}

\section{Oxygen as a Driving Gas for Nebulizers}

Most patients with obstructive lung diseases such as asthma, COPD, or bronchiectasis have additional airflow obstruction during exacerbations and require bronchodilator treatment. Nebulized bronchodilators such as salbutamol are widely used to treat this group of patients. For patients with asthma, it is recommended that the driving gas should be oxygen; however, many patients with COPD and some patients with bronchiectasis are at risk of hypercapnia, and the recommendation for such patients is to use an air-driven nebulizer with supplemental oxygen via nasal cannula if necessary to maintain a target saturation in the range of $88-92 \% .{ }^{1}$ If an air-driven or ultrasonic nebulizer is not available, clinicians can use multiple doses of bronchodilator using a metered-dose inhaler and a spacer. If an oxygen-driven nebulizer must be used, the advice is to limit this to $6 \mathrm{~min}$, which will deliver most of the bronchodilator drug, although there will still be some rise in the blood carbon dioxide level. ${ }^{1,73}$

\section{Carbon Monoxide Poisoning}

The hemoglobin molecule has a much greater affinity for carbon monoxide than for oxygen (and it displaces oxygen). Unfortunately, most pulse oximeters miscategorize carboxyhemoglobin as oxyhemoglobin, and the oximeter reading may be misleadingly normal despite significant arterial hypoxemia. This problem is further compounded by a normal blood oxygen tension in these circumstances. It is vitally important to measure the blood carbon monoxide level in all patients who might possibly have inhaled this gas and to give high-concentration oxygen to accelerate the clearance of carbon monoxide from the hemoglobin molecule. This is one of the rare situations in which the pulse oximetry target is $100 \%$ until the blood carbon monoxide level has fallen to safe levels.

Hyperbaric oxygen may also be beneficial in severe cases of carbon monoxide poisoning. Although hyperbaric 


\section{OXYGEN Use IN CRITICAL ILLNESS}

oxygen accelerates the clearance of carbon monoxide from the bloodstream, the evidence for improved clinical outcomes is weak but increasing. ${ }^{74,75}$ Hyperbaric oxygen is outside the scope of this review, except to say that it is considered to be effective in the management of decompression illness or arterial gas embolism, and it is sometimes used to accelerate recovery from carbon monoxide poisoning. Most other uses are regarded as experimental at the present time.

\section{Medically Managed Pneumothorax}

Pneumothorax is usually managed either by aspiration or by intercostal tube drainage. However, a small primary spontaneous pneumothorax may be allowed to self-absorb. In cases where a patient wishes to avoid drainage or if there is a contra-indication to drainage, the application of high-concentration oxygen will expedite the clearance of air from the pleural cavity. ${ }^{1}$

\section{Oxygen and Avoidance of Perioperative Wound Infection}

High concentrations of oxygen have been given to postoperative patients in the hope that this may reduce the risk of wound infection. Meta-analyses of this topic have largely been negative, with a suggestion that there may be some benefit in some subgroups. ${ }^{76}$ The largest such study actually suggested a delayed mortality risk in the group who received high-concentration oxygen. ${ }^{77,78}$

\section{Future Directions}

Although oxygen is an important treatment for hypoxemia, most available evidence suggests that oxygen has been overused for many decades and is still widely overused. There is no evidence of benefit from hyperoxemia in most medical conditions, but there is increasing evidence of harm from excessive oxygen use. If the calculations of $\mathrm{Chu}$ and colleagues ${ }^{23}$ are correct, it is possible that many thousands of deaths in the United States every year are caused by excessive oxygen therapy but not recognized as such.

The biggest challenge regarding oxygen use at present is to change the hearts and minds of the public and of health care professionals so that they recognize oxygen as a useful drug for a specific indication (hypoxemia), and not as a routine and essential measure to be applied without thought to all patients with serious medical conditions. The first requirement for this change will be recognition that oxygen is a drug, not a panacea. Like all drugs, it should be prescribed within its therapeutic range, and it can have serious side effects and can cause deaths if misused. However, like all "see-saw" problems in medicine, it is important not to swing too far in the opposite direction and thus ignore the dangers of hypoxemia. National audits in the United Kingdom have shown a very slow improvement in the proportion of patients using oxygen who have a prescription since national guidelines were first published in 2008 (Table 4). ${ }^{65}$

It is already becoming evident that early 21 st-century advice to aim for normal or near-normal oxygen saturation ranges such as $94-98 \%$ for most seriously ill patients was probably overly generous. ${ }^{1}$ It may be harmful to push the $\mathrm{S}_{\mathrm{pO}_{2}}$ above $96 \%$ with the use of supplemental oxygen, and lower target ranges such as $92-96 \%$ or even $90-94 \%$ have been proposed. ${ }^{23,53}$ It is likely that future research will define optimal target ranges for specific medical conditions, just as there is consensus at present that most patients with a history of hypercapnia should have a target range of $88-92 \% .1$

The situation in critical care units is even more complex than in the emergency room or the admissions unit. The present consensus is to aim for saturations in the low $90 \mathrm{~s}$ for most ventilated patients, and some authors propose permissive hyperoxemia at lower levels, especially for patients with acute lung injury; clinical trials of this strategy are required as a matter of some urgency. ${ }^{6,13}$ It is likely that future studies will define optimal target ranges (and optimal ventilation strategies) for different subgroups of ventilated patients on critical care units. In the meantime, there is a great deal of evidence that untreated hypoxemia and iatrogenic hyperoxemia are both harmful and should both be avoided. The former hazard is much feared and very rare, but the latter hazard is still poorly recognized and very common.

\section{REFERENCES}

1. O'Driscoll BR, Howard LS, Earis J, Mak V; British Thoracic Society Emergency Oxygen Guideline Group; BTS Emergency Oxygen Guideline Development Group. BTS guideline for oxygen use in adults in healthcare and emergency settings. Thorax 2017;72(Suppl 1):ii1-ii90.

2. Lanman JT, Guy LP, Dancis J. Retrolental fibroplasia and oxygen therapy. J Am Med Assoc 1954;155(3):223-226.

3. Downs JB. Has oxygen administration delayed appropriate respiratory care? Fallacies regarding oxygen therapy. Respir Care 2003; 48(6):611-620.

4. Hale KE, Gavin C, O'Driscoll BR. Audit of oxygen use in emergency ambulances and in a hospital emergency department. Emerg Med J 2008;25(11):773-776.

5. Smith GB, Prytherch DR, Watson D, Forde V, Windsor A, Schmidt $\mathrm{PE}$, et al. $\mathrm{SpO}(2)$ values in acute medical admissions breathing airimplications for the British Thoracic Society guideline for emergency oxygen use in adult patients? Resuscitation 2012;83(10):12011205.

6. Slutsky AS. Consensus conference on mechanical ventilation-Jan 28-30, 1993 at Northbrook, Illinois, USA. Part I. European Society of Intensive Care Medicine, the ACCP and the SCCM. Intensive Care Med 1994;20(1):64-79. 


\section{OXYGEN Use IN CRITICAL ILLNESS}

7. Siemieniuk RAC, Chu DK, Ha-Yeon Kim L, Guell-Rous MR, Alhazanni W, et al. Oxygen therapy for acutely ill medical patients: a clinical practice guideline. BMJ 2018;363:k41069.

8. Kelly FE, Fong K, Hirsch N, Nolan JP. Intensive care medicine is 60 years old: the history and future of the intensive care unit. Clin Med (Lond) 2014;14(3):376-379.

9. Rachmale S, Li G, Wilson G, Malinchoc M, Gajic O. Practice of excessive FIO2 and effect on pulmonary outcomes in mechanically ventilated patients with acute lung injury. Respir Care 2012;57(11): 1887-93.

10. de Jonge E, Peelen L, Keijzers PJ, Joore H, de Lange D, van der Voort PH. Association between administered oxygen, arterial partial oxygen pressure and mortality in mechanically ventilated intensive care unit patients. Crit Care 2008;12(6):R156.

11. Eastwood G, Bellomo R, Bailey M, Taori G, Pilcher D, Young P, Beasley R. Arterial oxygen tension and mortality in mechanically ventilated patients. Intensive Care Med 2012;38(1):91-98.

12. O'Driscoll BR, Dark P, Wijesinghe M, McAuley D. Oxygen use is becoming more conservative on intensive care units in the UK. Tho$\operatorname{rax}$ 2016;71(Suppl 3):A176.

13. Martin DS, Grocott MPW. Oxygen therapy in critical illness: precise control of arterial oxygenation and permissive hypoxemia. Crit Care Med 2013;41(2):423-432.

14. Smith JL. The pathological effects due to increase of oxygen tension in the air breathed. J Physiol 1899;24(1):19-35.

15. Freeman BA, Crapo JD. Hyperoxia increases oxygen radical production in rat lungs and lung mitochondria. J Biol Chem 1981; 256(21):10986-10992.

16. Barazzone C, Horowitz S, Donati YR, Rodriguez I, Piguet PF. Oxygen toxicity in mouse lung: pathways to cell death. Am J Respir Cell Mol Biol 1998;19(4):573-581.

17. Griffith DE, Holden WE, Morris JF, Min LK, Krishnamurthy. Effects of common therapeutic concentrations of oxygen on lung clearance of 99mTc DTPA and bronchoalveolar lavage albumin concentration. Am Rev Respir Dis 1986;134(2):233-237.

18. Farquhar H, Weatherall M, Wijesinghe M, Perrin K, Ranchord A, Simmonds M, Beasley R. Systematic review of studies of the effect of hyperoxia on coronary blood flow. Am Heart J 2009;158(3):371377.

19. Thomson AJ, Webb DJ, Maxwell SR, Grant IS. Oxygen therapy in acute medical care. BMJ 2002;324(7351):1406-1047.

20. Wang $\mathrm{CH}$, Chang WT, Huang $\mathrm{CH}$, Tsai MS, Yu PH, Wang AY, et al. The effect of hyperoxia on survival following adult cardiac arrest: a systematic review and meta-analysis of observational studies. Resuscitation 2014;85(9):1142-1148.

21. Damiani E, Adrario E, Girardis M, Romano R, Pelaia P, Singer M, Donati A. Arterial hyperoxia and mortality in critically ill patients: a systematic review and meta-analysis. Crit Care 2014; 18(6):711.

22. Helmerhorst HJ, Roos-Blom MJ, van Westerloo DJ, de Jonge E. Association between arterial hyperoxia and outcome in subsets of critical illness: a systematic review, meta-analysis, and metaregression of cohort studies. Crit Care Med 2015;43(7):15081519.

23. Chu DK, Kim LHY, Young PJ, Zamiri N, Almenawer SA, Jaeschke R, et al. Mortality and morbidity in acutely ill adults treated with liberal versus conservative oxygen therapy (IOTA): A systematic review and meta-analysis. Lancet 2018;391(10131):16931705 .

24. Kilgannon JH, Jones AE, Shapiro NI, Angelos MG, Milcarek B, Hunter $\mathrm{K}$, et al. Association between arterial hyperoxia following resuscitation from cardiac arrest and in-hospital mortality. JAMA 2010;303(21):2165-2171.
25. Kilgannon JH, Jones AE, Parrillo JE, Dellinger RP, Milcarek B, Hunter K, et al. Relationship between supranormal oxygen tension and outcome after resuscitation from cardiac arrest. Circulation 2011; 123(23):2717-2722.

26. Bellomo R, Bailey M, Eastwood GM, Nichol A, Pilcher D, Hart GK, et al. Arterial hyperoxia and in-hospital mortality after resuscitation from cardiac arrest. Crit Care 2011;15(2):R90.

27. Elmer J, Scutella M, Pullalarevu R, Wang B, Vaghasia N, Trzeciak S; Pittsburgh Post-Cardiac Arrest Service (PCAS). The association between hyperoxia and patient outcomes after cardiac arrest: analysis of a high-resolution database. Intensive Care Med 2015;41(1): 49-57.

28. Helmerhorst HJ, Arts DL, Schultz MJ, van der Voort PH, AbuHanna A, de Jonge E, van Westerloo DJ. Metrics of arterial hyperoxia and associated outcomes in critical care. Crit Care Med 2017; 45(1):187-195.

29. Rincon F, Kang J, Maltenfort M, Vibbert M, Urtecho J, Athar MK, et al. Association between hyperoxia and mortality after stroke: a multicenter cohort study. Crit Care Med 2014;42(2): 387-396.

30. Rønning OM, Guldvog B. Should stroke victims routinely receive supplemental oxygen? A quasi-randomized controlled trial. Stroke 1999;30(10):2033-2037.

31. Roffe C, Nevatte T, Sim J, Bishop J, Ives N, Ferdinand P, et al. Effect of routine low-dose oxygen supplementation on death and disability in adults with acute stroke: the Stroke Oxygen Study Randomized Clinical trial. JAMA 2017;318(12):1125-1135.

32. Rincon F, Kang J, Vibbert M, Urtecho J, Athar MK, Jallo J. Significance of arterial hyperoxia and relationship with case fatality in traumatic brain injury: a multicentre cohort study. J Neurol Neurosurg Psychiatry 2014;85(7):799-805.

33. Atar D. Should oxygen be given in myocardial infarction? BMJ 2010;340:c3287.

34. Ranchord AM, Argyle R, Beynon R, Perrin K, Sharma V, Weatherall $\mathrm{M}$, et al. High-concentration versus titrated oxygen therapy in STelevation myocardial infarction: a pilot randomized controlled trial. Am Heart J 2012;163(2):168-175.

35. Stub D, Smith K, Bernard S, Nehme Z, Stephenson M, Bray JE, et al.; AVOID Investigators. Air versus oxygen in ST-segment-elevation myocardial infarction. Circulation 2015;131(24):2143-2150.

36. Hofmann R, James SK, Jernberg T, Lindahl B, Erlinge D, Witt N, et al. Oxygen therapy in suspected acute myocardial infarction. N Engl J Med 2017;377(13):1240-1249.

37. Sepehrvand N, James SK, Stub D, Khoshnood A, Ezekowitz JA, Hofmann R. Effects of supplemental oxygen therapy in patients with suspected acute myocardial infarction: a meta-analysis of randomised clinical trials. Heart 2018;104(20):1691-1698.

38. Suzuki S, Eastwood GM, Glassford NJ, Peck L, Young H, GarciaAlvarez M, et al. Conservative oxygen therapy in mechanically ventilated patients: a pilot before-and-after trial. Crit Care Med 2014; 42(6):1414-1422.

39. Suzuki S, Eastwood GM, Goodwin MD, Noë GD, Smith PE, Glassford $\mathrm{N}$, et al. Atelectasis and mechanical ventilation mode during conservative oxygen therapy: a before-and-after study. J Crit Care 2015;30(6):1232-1237.

40. Eastwood GM, Tanaka A, Espinoza ED, Peck L, Young H, Mårtensson J, et al. Conservative oxygen therapy in mechanically ventilated patients following cardiac arrest: a retrospective nested cohort study. Resuscitation 2016;101(1):108-114.

41. Panwar R, Hardie M, Bellomo R, Barrot L, Eastwood GM, Young PJ et al. Conservative versus liberal oxygenation targets for mechanically ventilated patients: a pilot multicenter randomized controlled trial. Am J Respir Crit Care Med 2016;193(1):43-51. 


\section{OXYGEN Use IN CRITICAL ILLNESS}

42. Helmerhorst HJ, Schultz MJ, van der Voort PH, Bosman RJ, Juffermans NP, de Wilde RB, et al. Effectiveness and clinical outcomes of a two-step implementation of conservative oxygenation targets in critically ill patients: a before and after trial. Crit Care Med 2016; 44(3):554-63.

43. Girardis M, Busani S, Damiani E, Donati A, Rinaldi LM, Morelli A, et al. Effect of conservative vs conventional oxygen therapy on mortality amongst patients in an Intensive Care Unit. JAMA 2016; 316(15):1583-1589.

44. Young PJ, Mackle DM, Bailey MJ, Beasley RW, Bennett VL, Deane $\mathrm{AM}$, et al. Intensive care unit randomised trial comparing two approaches to oxygen therapy (ICU-ROX): results of the pilot phase. Crit Care Resusc 2017;19(4):344-354.

45. Asfar P, Schortgen F, Boisramé-Helms J, Charpentier J, Guerot E, Megarbane B, et al. Hyperoxia and hypertonic saline in patients with septic shock (HYPERS2S): a two-by-two factorial, multicentre, randomised, clinical trial. Lancet Respir Med 2017;5(3): 180-190.

46. O'Driscoll BR, Bakerly ND, Caress AL, Roberts J, Gaston M, Newton M, Yorke J. A study of attitudes, beliefs and organisational barriers related to safe emergency oxygen therapy for patients with COPD (chronic obstructive pulmonary disease) in clinical practice and research. BMJ Open Respir Res 2016;3:e000102.

47. Kelly CA, Lynes D, O'Brien MR, Shaw B. A wolf in sheep's clothing? Patients' and healthcare professionals' perceptions of oxygen therapy: an interpretative phenomenological analysis. Clin Respir J 2018;12(2):616-632.

48. Rotsztain A, Haddad R, Canter HG. Blood gas changes during voluntary hyperventilation in normal and disease states. Am Rev Respir Dis 1970;102(2):205-212.

49. Hoffman CE, Clark RT Jr, Brown EB Jr. Blood oxygen saturations and duration of consciousness in anoxia at high altitudes. Am J Physiol 1946;145(3):685-692.

50. Comroe JH Jr, Bahnson ER, Coates EO Jr. Mental changes occurring in chronically anoxemic patients during oxygen therapy. $\mathrm{J}$ Am Med Assoc 1950;143(12):1044-1048

51. Boycott AE, Haldane JS. The effects of low atmospheric pressures on respiration. J Physiol 1908;37(5-6):355-377.

52. Yoneda I, Tomoda M, Tokumaru O, Sato T, Wantanabe Y. Time of useful consciousness determination in aircrew members with reference to prior altitude chamber experience and age. Aviat Space Environ Med 2000;71(2):72-76.

53. Beasley R, Chien J, Douglas J, Eastlake L, Farah C, King G, et al. Thoracic Society of Australia and New Zealand oxygen guidelines for acute oxygen use in adults: 'swimming between the flags'. Respirology 2015;20(8):1182-1191.

54. Soar J, Deakin C, Lockey A, Nolan J, Perkins G. Resuscitation Guidelines 2015 Adult Life Support. London: Resuscitation Council UK, 2015.

55. Zhang J, Lin L, Pan K, Zhou J, Huang X. High-flow nasal cannula therapy for adult patients. J Int Med Res 2016;44(6):1200-1211.

56. Levy SD, Alladina JW, Hibbert KA, Harris RS, Bajwa EK, Hess DR. High-flow oxygen therapy and other inhaled therapies in intensive care units. Lancet 2016;387(10030):1867-1878.

57. Ashraf-Kashani N, Kumar R. High-flow nasal oxygen therapy. BJA Educ 2017;17:57-62

58. Monro-Somerville T, Sim M, Ruddy J, Vilas M, Gillies MA. The effect of high-flow nasal cannula oxygen therapy on mortality and intubation rate in acute respiratory failure: a systematic review and meta-analysis. Crit Care Med 2017;45(4):e449-e456.

59. Ni YN, Luo J, Yu H, Liu D, Liang BM, Liang ZA. The effect of high-flow nasal cannula in reducing the mortality and the rate of endotracheal intubation when used before mechanical ventilation compared with conventional oxygen therapy and noninvasive posi- tive pressure ventilation: a systematic review and meta-analysis. Am J Emerg Med 2018;36(2):226-233.

60. Ou X, Hua Y, Liu J, Gong C, Zhao W. Effect of high-flow nasal cannula oxygen therapy in adults with acute hypoxemic respiratory failure: a meta-analysis of randomized controlled trials. CMAJ 2017; 189(7):260-267.

61. Hernandez G, Vaquero C, Colinas L, Cuena R, Gonzalez P, Canabal A, et al. Effect of postextubation high-flow nasal cannula vs noninvasive ventilation on reintubation and postextubation respiratory failure in high-risk patients: a randomized clinical trial. JAMA 2016; 316(15):1565-1574.

62. Nedel WL, Deutschendorf C, Filho EMR. High-flow nasal cannula in critically ill subjects with or at risk for respiratory failure: a systematic review and meta-analysis. Respir Care 2017;62(1):123132

63. Ebmeier SJ, Barker M, Bacon M, Beasley RC, Bellomo R, Knee C, et al. A two-centre observational study of simultaneous pulse oximetry and arterial oxygen saturation recordings in intensive care patients. Anaesth Inten Care 2018;46(3):297-303.

64. Jochmans S, Vong LV, Rolin N, Sy O, Chelly J, Ellrodt O, et al. Efficiency of goal-directed oxygen delivery in ICU patients. Anaesthesiol Intensive Ther 2016;48(3):151-157.

65. O’Driscoll BR. British Thoracic Society Emergency Oxygen Audit Report 2015. London: British Thoracic Society, 2015. Available at: https://www.brit-thoracic.org.uk/document-library/qualityimprovement/audit-reports/emergency-oxygen-2015. Accessed July 13, 2019.

66. Hansen EF, Hove JD, Bech CS, Jensen JS, Kallemose T, Vestbo J. Automated oxygen control with O2matic during admission with exacerbation of COPD. Int J Chron Obstruct Pulmon Dis 2018;13: 3997-4003.

67. L'Her E, Jaber S, Verzilli D, Jacob C, Huiban B, Futier E, et al Automated oxygen administration versus conventional oxygen therapy after major abdominal or thoracic surgery: study protocol for an international multicentre randomised controlled study. BMJ Open 2019;9(1):e023833.

68. Pierson DJ. Translating evidence into practice. Respir Care 2009; 54(10):1386-1401

69. Sjoding MW. Translating evidence into practice in ARDS: teamwork, clinical decision support, and behavioural economic interventions. Curr Opin Crit Care 2017;23(5):406-411.

70. Kelly CA, Madden M. How do health-care professionals perceive oxygen therapy? A critical interpretive synthesis of the literature. Chron Respi Dis 2015;12(1):11-23.

71. Karthika M, Wong D, Nair SG, Pillai LV, Matthew CS. Lung ultrasound: the emerging role of respiratory therapists. Respir Care 2019;64(2):217-229.

72. Cavalcanti AB, Bozza FA, Machado FR, Salluh JI, Campagnucci VP, Vendramim P, et al. Effect of a quality improvement intervention with daily round checklists, goal setting, and clinician prompting on mortality of critically ill patients: a randomized clinical trial. JAMA 2016;315(14):1480-1490.

73. Bardsley G, Pilcher J, McKinstry S, Shirtcliffe P, Berry J, Fingleton $\mathrm{J}$, et al. Oxygen versus air-driven nebulisers for exacerbations of chronic obstructive pulmonary disease: a randomised controlled trial. BMC Pulm Med 2018;18(1):157.

74. Buckley NA, Juurlink DN, Isbister G, Bennett MH, Lavonas EJ. Hyperbaric oxygen for carbon monoxide poisoning. Cochrane Database Syst Rev 2011;4:CD002041.

75. Lin $\mathrm{CH}, \mathrm{Su}$ WH, Chen YC, Feng PH, Shen WC, Ong JR, et al. Treatment with normobaric or hyperbaric oxygen and its effect on neuropsychometric dysfunction after carbon monoxide poisoning: a systematic review and meta-analysis of randomized controlled trials. Medicine (Baltimore) 2018;97(39):e12456. 


\section{OXYGEN Use IN CRITICAL ILLNESS}

76. de Jonge S, Egger M, Latif A, Loke YK, Berenholtz S, Boermeester $\mathrm{M}$, et al. Effectiveness of $80 \%$ vs $30-35 \%$ fraction of inspired oxygen in patients undergoing surgery: an updated systematic review and meta-analysis. Br J Anaesth 2019;122(3):325-334.

77. Meyhoff CS, Wetterslev J, Jorgensen LN, Henneberg SW, Høgdall $\mathrm{C}$, Lundvall L, et al. Effect of high perioperative oxygen fraction on surgical site infection and pulmonary complications after abdominal surgery: the PROXI randomized clinical trial. JAMA 2009;302(14): 1543-1550.

78. Meyhoff CS, Jorgensen LN, Wetterslev J, Christensen KB, Rasmussen LS; PROXI Trial Group. Increased long-term mortality after a high perioperative inspiratory oxygen fraction during abdominal surgery: follow-up of a randomized clinical trial. Anesth Analg 2012; 115(4):849-854. 